\title{
Os caminhos do anjo das trevas: reflexões sobre poesia moderna no ensaio Contre l'obscurité, de Marcel Proust
}

\section{The ways of the dark angel: reflections about modern poetry on the Marcel Proust's essay Contre l'obscurité}

Iury Almeida e Belchior ${ }^{1}$

Resumo: Neste artigo, estudaremos o ensaio intitulado Contre I'obscurité, publicado na Revue Blanch em 1896, por Marcel Proust. Nele o escritor francês critica o Simbolismo, uma tendência literária de sua época. Segundo Proust, a obscuridade empreendida pelos jovens poetas simbolistas seria uma perspectiva muito objetiva da poesia, como se a sua espinha dorsal se nutrisse por enigmas linguísticos, portanto, sistemática e fechada. Assim, ele defende outro tipo de obscuridade, no sentido de uma poesia sentimental, possível através da união entre linguagem e pensamento, arte e memória. Para analisar os postulados proustianos, em particular a ideia de tipos diferentes de obscuridade, nós optamos por um diálogo com importantes críticos que se empenharam em compreender a poesia moderna, como Hugo Friedrich, Estrutura da Lírica Moderna, e Alfonso Berardinelli, em Da Poesia à Prosa.

Palavras-chave: Proust; Mallarmé; Poesia; Obscuridade; Simbolismo; Modernidade.

Abstract: In this paper, we study the essay Contre l'obscurité, published in the Revue Blanch in 1896, by Marcel Proust. In it the French writer criticizes the Symbolism, a literary tendency of his time. According to Proust, the obscurity undertaken by the young symbolist poets would be a very objective perspective of poetry, as if its backbone were nurtured by linguistic enigmas, therefore, systematic and closed. Then, he defends another type of obscurity, in the sense of a sentimental poetry, possible through the union between language and thought, art and memory. To analyze the proustian postulates, in particular the idea of different types of obscurity, we opted for a dialogue with important critics who enforced to understand modern poetry, such as Hugo Friedrich, in The Structure of the Modern Lyric, and Alfonso Berardinelli in From Poetry to Prose.

Keywords: Proust; Mallarmé; Poetry; Obscurity; Symbolism; Modernity. 
Incomensuráveis esforços são realizados na tentativa de apreender a poesia moderna. No clássico estudo de Friedrich, Estrutura da Lírica Moderna, dissonâncias e anormalidade marcam a poesia moderna, em oposição à serenidade e harmonia da prática poética anterior a esta. A negatividade, não em relação ao conteúdo, mas à forma, fomentaria um núcleo de categorias comuns a este tipo de poesia, dentre as quais uma que fascina: a obscuridade. A princípio, podemos compreendê-la como uma espécie de incomunicabilidade intencional; a poesia gerando uma tensão que tende mais à inquietude que à serenidade (FRIEDRICH, 1978, p.15).

Sem desqualificar o trabalho empreendido por Friedrich, que a partir de um apanhado histórico um tanto quanto linear tenta desenvolver a obscuridade como um denominador comum à poesia moderna, a reflexão sobre esta já se inclinava à pluralidade desde o século XIX. Em um ensaio publicado na Revue Blanch, em 1896, Marcel Proust discorre sobre esse conceito. Antes de prosseguirmos, vale mencionar que embora seja um escritor conhecido pelo monumental romance $\dot{A}$ la recherche du temps perdu, no momento que escreve o ensaio Contre l'obscurité sua obra derradeira nem tinha começado a ser escrita. Além disso, é importante deixar claro que Proust não se destacou como poeta, no sentido estrito do termo, sendo sua produção poética um conjunto bem tímido. Ainda assim, isso não desmerece sua empreitada crítica, pois, além de se mostrar um grande leitor, a discussão sobre obscuridade nesse ensaio pode ser parte da teoria estética que seria levada às últimas consequências no Em busca do tempo perdido (como foi traduzido o título de seu romance), contendo, portanto, o germe de sua concepção estilística.

Iniciando, já com suas peripécias retóricas, Proust segue criando uma espécie de jogo de espelhos em que, ao dar voz aos poetas da nova geração, diz o que eles pensam dos antigos, e respondendo às afirmações dos vanguardistas ele segue com uma espécie de diálogo que desde já nos remete a Platão, à maneira como este tratava a filosofia ${ }^{2}$. Ao perguntar aos jovens poetas se eles fazem parte da nova geração, o jovem crítico se coloca contemporâneo a eles (e de fato é), ainda que afirme que não os entenda, pois parece haver um pré-requisito para a compreensão da poesia: preparação e seleção prévias. Na sequência, ele concorda com os poetas jovens que é necessário uma iniciação para a compreensão da poesia, entretanto, esta iniciação não consiste em mero mecanismo formal, versos livres ou latinos, pois isto não seria mais que vains coquillages, sonores e vides (conchas vãs, sonoras e vazias). (PROUST, 1896, p.69) É importante esclarecer que o que Proust considera como poetas, vale tanto para os que escrevem em verso quanto para prosa. Além dessa noção ampla do termo poeta, os jovens poetas que ele menciona são os poetas simbolistas, movimento conhecido pelo experimentalismo e exploração de mecanismos estritamente linguísticos para alcançar seu efeito poético, como sons e grafia, o que demonstra ainda mais a sagacidade crítica da expressão utilizada por Proust.

No parágrafo seguinte, Proust $(1896$, p.69) finalmente expõe o l'erreur d'estétique (erro de estética) - importante sublinhar esta expressão - do qual acusa os poetas simbolistas. Os jovens poetas, ao se recusarem a adequar seu gênio, o que os impele à originalidade, às leis gerais da arte, e ao gênio permanente da língua, acabariam por gerar uma dupla obscuridade. Essa dupla obscuridade seria formada por dois aspectos: de um lado uma obscuridade de ideias e imagens, de outro, uma obscuridade

\footnotetext{
${ }^{2}$ Essa correlação é importante pela razão de Proust acusar os poetas simbolistas de estarem procedendo como filósofos ao desenvolverem uma poesia sistemática. Ressalta, pois, uma das muitas contradições proustianas, pois ao dar um tratamento mimético criando um diálogo, o crítico não deixa de estar, à moda platônica, filosofando também.
} 
gramatical. Os poetas simbolistas, de acordo com a hipótese de interlocução, afirmariam que sua obscuridade é a mesma de Racine e Victor Hugo, certa novidade no uso da linguagem e que esta evolução da língua é concomitante a evolução do pensamento, como se fosse próprio das inovações no campo das artes sempre serem recebidas com hostilidade. Em resposta, Proust afirma, ornado em agudas ironias, que o problema é a incoerência no uso da palavra obscuridade. Este, por sua vez, seria algo novo na Literatura e que é uma atitude prepotente acreditar que se está conduzindo o progresso das artes, a ponto do valor das obras que compõem o cânone serem subitamente invertidos, como se o mundo mudasse repentinamente através da vontade de um pequeno grupo. Numa réplica, os jovens poetas se comparariam aos filósofos Spinoza, Kant e Hegel, aussi obscurs qu'ils sont profonds (tão obscuros quanto profundos) (PROUST, 1896, p.70). Afirmariam que foi a obscuridade que garantiu a longevidade de seus sistemas e que a poesia simbolista seria equivalente, ela não é um mero devaneio, mas um sistema. Esta afirmação é a mea culpa que faltava para que o crítico os acuse de fazer uma confusão entre poesia e teoria, pois a verdade da razão seria diferente de uma verdade das artes, já que só o sentimento poderia conduzir o poeta ao coeur du monde (coração do mundo) (PROUST, 1896, p.70). Para ilustrar a validade dessa tese, parecendo até antecipar Freud, Proust afirma que a peça de Shakespeare, Macbeth, é uma filosofia sem ser filosofia, pois nos fornece uma verdade não sistemática, uma verdade dos instintos ${ }^{3}$. Dessa forma, essa obra seria uma amostra da boa obscuridade, densa e profunda, pois não estaria encerrada na obscuridade gramatical, numa incomunicabilidade, capsula protetora de uma exatidão sistemática. Isto se justifica pelo fato do filósofo se dirigir às nossas faculdades lógicas, enquanto o poeta não; a filosofia está para uma verdade científica e carece de certa pureza dos signos. Nesse ponto reside uma importante diferença entre a visão de Proust e dos poetas simbolistas, enquanto estes acreditavam que o fazer poético estaria vinculado à significação, aquele professava uma poética da evocação.

Esta diferença entre significação e evocação está, obviamente, vinculada à questão da memória. Proust já se coloca como um memorialista ao reconhecer que os próprios simbolistas aludem ao poder da palavra, du charme de son origine ou de la grandeur de son passé (do charme da sua origem ou da grandeza de seu passado), do impacto disso sobre nossa imaginação (PROUST, 1896, p.71). O problema é que ao limitar a poesia à significação, a perspectiva está muito mais para uma língua instrumental, uma segunda língua que aprendemos com determinado objetivo, que para os encantos e mistérios da nossa língua materna e seu poder de fazer da palavra une sorte de musique latente que le poète peut faire rèssoner em nous avec une douceur incomparable (um tipo de música latente que o poeta pode fazer ressoar em nós com uma doçura incomparável). (PROUST, 1896, p.71) Nessa altura do ensaio, vale mencionar que o crítico que escreve é o jovem Proust, por isso o exemplo de poeta preocupado com uma memória da língua seja Anatole France (1844-1924), escritor admirado que será renegado posteriormente, como o protagonista da Recherche, Marcel, se distanciará cada vez mais do personagem escritor, Bergotte. Ainda assim, essa comparação do poder de evocação da palavra à música, que pode fazer ressoar em nós algo esquecido, é importante tanto como um sinal da relação entre arte e memória, que será plenamente desenvolvida no romance, quanto como mais uma demonstração da agudeza crítica do prodígio Marcel Proust, ao utilizar uma imagem através do verbo réssoner e assim, contemplar uma

\footnotetext{
${ }^{3}$ É importante informar que a diferença entre competência da razão e dos sentimentos é um tópico nos escritos de Proust, está presente nesse ensaio, em Contre Sainte-Beuve (que foi escrito provavelmente em 1908) e também na Recherche. Além disso, a proposta de que a Arte provém dos instintos e, como veremos ainda neste trabalho, da relação desta com a memória, é algo que encontra grande fundamentação na teoria freudiana, ainda que não haja provas de que Proust leu a obra de Freud.
} 
questão que será muito cara aos simbolistas - e particularmente a Mallarmé - a sonoridade e sua possibilidade de leitura, de ser sentida, ainda que sem um referente explícito, ou ao menos, um referente que não seja nada além da própria poesia.

Prosseguindo, Proust passa ao exame de uma terceira razão que os simbolistas poderiam utilizar para se justificarem: as ideias e sensações obscuras. Estas seriam ideias e sensações mais sofisticadas, mais raras e de difícil expressão, oposição às sensações mais claras, apolínias e correntes. O poeta, por ter um ponto de vista menos ordinário, teria um especial interesse por este tipo de matéria. Proust responde a este argumento com uma imagem que pode ser um precioso índice de seu posicionamento como artista-crítico e, por conseguinte, revelar uma tensão do seu posicionamento (inclusive político). Ele diz que se o poeta tem atração por essas ideias obscuras, ele deve torná-las mais claras; s'il parcourt la nuit, que ce soit comme l'Ange de Ténèbres, en y portent la lumière (se ele percorre a escuridão, que seja como o Anjo das Trevas, trazendo-as à luz). (PROUST, 1896, p.71)

Esta imagem tem íntima relação com um elemento muito importante para a reflexão sobre a obscuridade: a recepção da poesia. Portanto, finalmente partimos para o argumento geralmente invocado pelos simbolistas em defesa de sua obscuridade: ela serviria para proteger a sua obra do vulgo. A linguagem-fortaleza, de uma poesia para especialistas, serviria para proteger a obra de arte de um público medíocre, o que justificaria sua incomunicabilidade. Entretanto, para o crítico, que não poupa acidez ao dizer que, nesse caso, há um erro quanto a quem seja o vulgo da situação, a preocupação em agradar ou desagradar o público revela uma ideia infantil e medíocre; infantil por acreditar que a poesia possa ser compreendida através do pensamento (e nesse caso retornamos a dualidade já explorada, da diferença entre poesia e filosofia), e medíocre por limitar a obra de arte a atender ou não a demanda do público. Essa ânsia pueril, em utilizar uma expressão fácil para bajular o público ou uma expressão hermética para restringi-lo, impede que se tenham preocupações verdadeiramente estéticas com a poesia, e, portanto, indiferente do caminho escolhido, só agrade a leitores de segunda categoria. Proust acusa a geração simbolista de negligenciar o tempo e o espaço ao querer revelar apenas as verdades universais e assim negligenciar que o universal está presente no particular. Quanto mais particular, mais universal. Dessa forma, para o autor da Recherche, se a poesia utiliza uma língua conhecida pelos seus leitores, não há necessidade de utilizar expressões mudas, pois mesmo as novidades ressoaram como traduzíveis. É instigante que, em resposta, Mallarmé publica um artigo no mesmo número da Revue Blanche, com o título de Les mystère dans le lettres, e refuta: Il doit y avoir quelque chose d'occulte au fond de tous, je crois décidément à quelque chose d'abscons, signifiant fermé et caché (Deve haver algo de oculto no fundo de todos, eu acredito decididamente em algo de absconso, significante fechado e escondido). (MALLARMÉ, 1896, p.214)

Partindo dessa breve apresentação de Contre l'Obscurité poderemos fazer algumas considerações teóricas. É necessário salientar que não será preciso fazer justiça à Mallarmé, pois o leitor informado saberá que a própria perspectiva crítica proustiana valoriza aspectos da poesia simbolista, da qual o poeta mencionado é o grande expoente. Ademais, se trata de uma perspectiva, que as próprias considerações teóricas terão o potencial de corrigir as deformidades. Desse modo, aquelas afirmações mais totalizadoras serão balizadas de forma razoável.

Seja como for, nenhuma hipótese é mais totalizadora que aquela que afirme que exista a obscuridade. É nesse sentido que o ensaio de Proust nos interessa, pois, historicamente, ele se insere 
como um dos pioneiros a refletir sobre a poesia moderna considerando tipos de obscuridade. Mesmo assim, ele realiza seu intento com certa imprecisão, se considerarmos que sua visão de poesia se estende a autores de romances ${ }^{4}$. A dificuldade advém da tentativa de definir a obscuridade em si mesma, pois tanto ela, quanto a própria definição de clareza, são conceitos relativos (BERARDINELLI, 2007, p.127). Ainda que possamos afirmar que exista a poesia, ou uma história da poesia, não podemos constatar a existência de uma única característica, mas de várias. Se considerarmos as diferenças da língua ou mesmo as nacionais, essas características se multiplicam vertiginosamente. Desse modo, da mesma forma que não encontramos um conceito plenamente capaz de definir a modernidade, não há como definir, sem o ônus praticamente impossível de percorrer toda a produção poética moderna, a obscuridade. Isto sem mencionar a questão da recepção que a envolve; seria ainda mais difícil presumir todos os leitores, com todas as suas especificidades e diferenças. Ainda assim, seu apontamento por parte de Hugo Friedrich tem o mérito de nos indicar uma mudança de perspectiva; a poesia moderna não é o caminho de um jardim de paz e serenidade. Não que a paz e a serenidade não estejam mais ao nosso alcance, mas agora há tantos caminhos que a própria indecisão contingencial já nos causa inquietude.

Valorizando o empenho de Estrutura da Lírica Moderna, e ao mesmo tempo lúcido quanto às suas limitações, o filosofo italiano Alfonso Berardinelli tenta encontrar uma órbita possível em que a obscuridade possa ser constatada como um denominador comum, ainda que ela possa estar em posições diferentes e concomitantes. Apesar da multiplicidade de caminhos: "nas formas de obscuridade moderna há algo de irredutível: um dissídio que se representa continuamente e que força a linguagem poética sempre para aquém ou além da comunicação social predominante, rumo à utopia ou ao silêncio, à afasia ou ao idioleto." (BERARDINELLI, 2007, p.133) Assim, ao considerar essa área, ele pode ir além da primeira de suas duas hipóteses - que seria a de que cada autor é obscuro à sua maneira, no sentido de uma estética pluralista - em direção à segunda - a de que há quatro tipos de obscuridade presentes sincronicamente e diacronicamente, nesse caso até sugerindo uma evolução histórica. Sincronicamente as variações da obscuridade podem ser constatadas em autores que são contemporâneos entre si, mas que percorrem trajetos distintos.

Para melhor esclarecimento, trataremos, ainda que resumidamente, de cada um dos quatro tipos de obscuridade. O primeiro é denominado solidão e singularidade, é caracterizado pela postura do autor que se projeta no leitor. Este, por sua vez, passa a ser uma espécie de duplo do autor e a situação de comunicação é praticamente de um monólogo. 0 que não surpreende é que o maior exemplo desse primeiro tipo de obscuridade seja Hamlet:

Essa é a situação de Hamlet, oscilante, instável e destruidora de todo vínculo com o ambiente (de um lado, fala a si mesmo, de outro, fala por provocação, fingindo-se de louco). O movimento em direção à obscuridade nasce com uma situação que poderíamos definir hamletiana e misantrópica da linguagem. (BERARDINALLI, 2007, p.136)

O segundo tipo de obscuridade denomina-se profundidade e mistério. Caracteriza-se por uma inclinação às profundezas da realidade, já que a superficialidade, a realidade comum e compartilhada não agrada mais ao poeta. Segundo o filósofo italiano, isso já aparece em Hölderlin e Leopardi, mas ao

\footnotetext{
${ }^{4}$ Isso não significa que há ausência de critério na amplitude que Proust utiliza, pois se considerarmos a Literatura como uma grande série, poesia e romance são elementos distintos que tem muitos pontos de intersecção. Além disso, vale salientar que a obscuridade e seus possíveis equivalentes teóricos, como a literariedade, terão grande influência no romance. (BERARDINELLI, 2007, p.142)
} 
mesmo tempo se concentra nos simbolistas (o que já é um dado importante para o saldo de nossas reflexões). Como o mundo visível não é mais interessante, há necessidade de novos utensílios para que o poeta-explorador mergulhe nas profundezas, ou seja, há necessidade de uma linguagem apropriada, diferente da comunicação habitual, em que:

Se os objetos singulares sensíveis comparecem, é para recorrer a outra coisa, à profundidade e ao mistério que se abrem às suas costas, criando efeitos de vertigem. Os objetos se tornam símbolos, epifanias, manifestações momentâneas, inesperadas e radiantes de uma realidade que está além, atrás ou mais adiante. (BERARDINELLI, 2007, p.137)

Provocação é o terceiro tipo de obscuridade. Embora ela pareça apenas uma postura do poeta em relação ao mundo, sua revolta, seu descaso ou rebeldia, ela passa a integrar a dimensão da linguagem para comportar determinados conteúdos. Um exemplo emblemático desse tipo é Baudelaire:

A estética do feio e o fascínio da corrupção, da deterioração, do horror, do vício, dos estados alterados e patológicos de consciência, não criam, com Baudelaire, apenas a personagem da poeta como dandy, mas também determinam inteiramente o cenário e a linguagem das Fleurs du mal. (BERARDINELLI, 2007, p.138)

Por fim, o quarto tipo de obscuridade é denominado Jargão. Nele, a modernidade não está cansada de si mesma, não procura se resolver; se há uma crise de sentido, toda impossibilidade do sentido será aproveitada. O silêncio, o vazio, a intraduzibilidade é objeto de contemplação. Seu maior representante é, sem sombra de dúvidas, o próprio Mallarmé. Na prática poética, seu efeito é uma maior especificidade de linguagem. Esta se torna uma espécie de fortaleza em que o poeta aprisionará a poesia, somente aos especialistas será possível, não resgatá-la, mas contemplá-la em seu cárcere, pois:

Quando a obscuridade, como característica geral, genérica e abstrata da poesia moderna, se torna jargão, isto é, língua especial e especializada, aceita enquanto tal no pluralismo das especializações culturais, então o radicalismo estético moderno está acabado: já não surpreende nem escandaliza nem oferece um acréscimo de conhecimento, e o choque é assimilado. BERARDINELLI, 2007, p.140)

Os quatro tipos de obscuridade apresentados são muito significativos para a diatribe explorada no ensaio de Marcel Proust. Antes de qualquer coisa, cumpre esclarecer que seu caráter esquemático não é capaz de resolver as várias tensões internas que encontramos ao examinar cada poeta. Mas como já afirmado anteriormente, trata-se de uma hipótese sobre a obscuridade. Por conseguinte, ela não exclui a primeira, mais pluralista e monográfica, mas explora algumas das nuances e possibilita uma atitude crítica mais comparativa, o que fomenta movimentos intelectuais sofisticados e até uma riqueza epistemológica. Em outras palavras, ela é uma ramificação muito instigante do clássico estudo desenvolvido por Friedrich.

Quanto ao ensaio de Marcel Proust, os quatro tipos de obscuridade nos permitem explorar melhor as diferenças ali encontradas. Primeiramente, é preciso ressaltar que embora sejam quatro, eles percorrem um arco entre dois polos extremos que podemos alocar facilmente em Contre I'Obscurité, "o espaço artístico se divide entre o território da regressão mágica e o da modernização tecnológica" (BERARDINALLI, 2007, p.134). É evidente que a posição de Proust é voltada mais para a 
regressão mágica, pela defesa da tradição, da comunicação e até, em alguns momentos, de uma estética idealista. Quando ele aborda a memória da língua e trata de seu poder de ressoar em nós algo já esquecido, ele parece estar aludindo claramente à noção de memória cultural (ou coletiva). Em oposição a História, a memória é emocional e mágica (NORA, 1993. p.9). A relação entre arte, ou mais especificamente, entre poesia e memória, fica evidente na perspectiva do jovem crítico. No extremo oposto, encontramos o simbolismo personificado na engenharia de Mallarmé, que com seu experimentalismo, praticamente implode a linguagem, ou ao menos, rompe radicalmente com alguma persistência do passado das artes. Em oposição à magia da evocação, Mallarmé se empenha no pensamento explorando espaços rumo à significação, o que representa "a firme defesa do ponto de vista da poesia e do poeta como lugar possível de um discurso sobre a história." (SISCAR, 2011. p.92) Embora a analogia com a diferença entre memória e história sugeridas pelo famigerado par magia e técnica pareça evidente, ao explorarmos a convergência entre as visões que foram debatidas no ensaio de Proust e os quatro tipos de obscuridade, constataremos que elas não formam uma visão tão binária assim, já que, "frequentemente essas figuras contrapostas se sobrepõem em um mesmo autor. $E$ isso também ocorre em relação aos quatro tipos - ou aos quatro caminhos - de obscuridade". (BERARDINALLI, 2007, p.134)

Quanto ao primeiro tipo - solidão e singularidade - parece evidente que ele se adequa mais a perspectiva proustiana, não só pelo fato de Hamlet ser o grande exemplo (e Proust mencionar Macbeth como amostra do tipo de obscuridade que prefere), mas pela própria característica do particular como canal para expressão de um espírito absoluto. Lembrando que, na perspectiva do jovem crítico, quanto mais particular mais universal. E, com o perdão de certo anacronismo, já que nesse instante de Contre I'Obscurité a Recherche não tinha começado a ser escrita, e mediante uma autorização para conceber o estilo levado a cabo no romance como um feito poético (logo, mediante a uma ampliação do sentido da palavra poeta), vale ressaltar que Proust tem seu romance narrado em primeira pessoa, numa profusão de exaustivos monólogos, como se o leitor fosse seu duplo e não se desesperasse diante do seu belo e prolixo movimento reflexivo. No que diz respeito aos simbolistas, esse tipo de obscuridade não parece ser adequado, pois ainda que ele presuma o seu interlocutor como uma extensão de si mesmo (alto grau de subjetividade), a linguagem utilizada tem certo vínculo comunicativo.

No segundo tipo, profundidade e mistério, a visão do crítico concorda com os simbolistas a respeito da preferência do poeta pelas sensações e ideias obscuras. A divergência aponta para a maneira de tratamento. No ensaio, os jovens poetas dizem que é necessária uma linguagem diferente para tratar dessas sensações, o crítico responde com a bela e emblemática imagem do Anjo das Trevas, que deve buscar esclarecê-las. Sobre esse aspecto, Berardinelli (2007, p.137) afirma que "é necessária uma linguagem diversa em relação à usual, da comunicação, ou à linguagem tradicional da poesia". Quanto a esse aspecto, embora Proust, tanto no ensaio quanto em seu romance, que inicia com uma cena que o narrador está meio sonolento e não consegue distinguir o quarto em que repousa, além das tantas outras em que a realidade exterior é extremamente questionada, podemos concluir que este tipo de obscuridade não se efetiva, por mais que haja uma inclinação a ela. ${ }^{5}$

\footnotetext{
${ }^{5}$ Se considerarmos que em profundidade e mistério os objetos aparecem como sombras de uma realidade mais profunda, talvez essa linguagem já esteja efetiva em Proust. Em seu romance, os objetos sensoriais aparecem como pontes para realidades profundas, o maior
} 
Sobre o terceiro tipo, provocação, não identificamos situação análoga sendo discutida no ensaio de Proust. De qualquer forma, poderíamos questionar, eventualmente, se a própria linguagem utilizada por um Mallarmé em um Coup de Dés (Lance de Dados) não seria um estímulo provocativo. Concluímos que não, pois esse tipo de obscuridade provocativa está muito mais relacionado ao debate ético-moral através de uma linguagem que choca, mas ainda assim comunica as verdades grotescas, áridas e pérfidas. O referido poema não provoca, mas está fechado, muito mais relacionado com o quarto tipo de obscuridade. Ainda tomando de empréstimo a abrangência do termo poeta, poderíamos encontrar indícios desse tipo de obscuridade no romance proustiano, não apenas pela exposição dos vícios, da hipocrisia aristocrática, do ciúme doentio, da homossexualidade e do sadismo, mas pela forte presença de Baudelaire durante Em busca do tempo perdido, manifesta tanto com referências às Fleurs du Mal quanto ao ensaio Le peintre de la Vie moderne (O pintor da Vida moderna).

Por fim, o quarto tipo de obscuridade - jargão - é o verdadeiro inimigo em Contre l'Obscurité, Para o crítico, é essencial que a poesia tenha o mínimo de potência comunicativa. Nesse sentido, a poesia praticada por Mallarmé seria uma poesia fechada em si mesma, o que, de certa forma, sustentaria as acusações feitas por Marcel Proust: de que seria uma poesia preocupada em agradar ou desagradar o público enquanto restrição, de que seria uma poesia para iniciados e de que teria muito mais preocupações lógicas para nutrir-se enquanto sistema que preocupações estéticas. Em convergência com elas, Berardinelli discorre que:

\begin{abstract}
Os poetas falam entre si, ou para um círculo diminuto. A linguagem da busca pelo absoluto produz, em Mallarmé, um absoluto da linguagem, uma linguagem-fortaleza, uma linguagem-prisão, uma turris eburnea. A língua da poesia se especializa. Cria um antimundo. Funciona como uma máquina, procedendo a uma meticulosa abrasão de todo conceito, imagem e valor herdados. $\mathrm{O}$ ato poético passa a ser culto e apologia de si mesmo. Desses pressupostos nasce uma obscuridade que poderíamos definir de 'Sublime Niilismo'. (BERARDINELLI, 2007, p.141)
\end{abstract}

Em contrapartida, os simbolistas como vanguarda exerceram um papel político importante, ao realizar, com essa recusa do mundo, uma grande negação do mundo burguês. A poesia parecia ter atingido seu ápice, o experimentalismo radical intentava criar uma arte que fosse a única finalidade em si mesma. Ou, como atesta Berardinelli (2007, p.131), "as novas vanguardas trabalhavam na consolidação teórica da estética da modernidade". A obscuridade máxima era a prova derradeira de que um escritor estava se movendo no âmago da própria modernidade. Por essa razão, é natural que Proust, ao advogar em defesa da cultura nos pareça conservador, pois seu posicionamento estético, ao tomar a poesia como sentimental, arte como autoconsciência crítica e histórica, de alguma maneira defenda instâncias burguesas de poder. Ou talvez, seja apenas um pré-requisito de quem acredite na possibilidade de mudar a cultura por dentro da cultura. Ou ainda, já aspirando ares do modernismo, ele estivesse professando ser possível resolver os dilemas de seu tempo mediante o diálogo com a tradição, a possibilidade de sentido numa relação entre particular e universal. Em suma, são visões diferentes do processo em curso: a modernidade. Em conjunto, as duas desempenham funções importantes. Ao questionarem radicalmente 0 mundo, os simbolistas fecham a possibilidade para a continuidade do mundo a partir de outra postura, 0 que leva "à eliminação da ideia de obra, de arte e de obra de arte." (BERARDINELLI, 2007, p.142) Ao 
mesmo tempo, as vanguardas inauguram uma nova poesia, um novo público leitor, uma crítica especializada e acadêmica. Um exemplo disso é que a esquemática tipologia de Alfonso Berardinelli, ao ampliar a noção de obscuridade de Hugo Friedrich não esgota a questão da obscuridade, pelas muitas particularidades que já abordamos. Apesar da impossibilidade totalizante da teoria diante de um objeto sempre fugidio que é a poesia, não devemos nos frustrar pela sua contínua não instrumentalização ${ }^{6}$. Muito pelo contrário, por tantas vezes nos fazer ultrapassar os limites do fôlego, num exaustivo empenho crítico e teórico, é que a poesia moderna demonstra seu valor como objeto de estudo. Por essa razão, podemos afirmar (talvez contrariando Marcel Proust) que depois de Mallarmé, o mundo finalmente está pronto para a poesia, tem sofisticados instrumentos para lidar com ela em todas as variações de obscuridade. Se não podemos apreendê-la totalmente, podemos passear pelos caminhos escuros, pelo breve caminho da vida, iluminando um pouco mais, como um Anjo das Trevas...

\section{Referências Bibliográficas:}

BERARDINELLI, Alfonso. Da poesia à prosa. Tradução de Maurício Santana Dias. São Paulo: Cosac Naify, 2007. FRIEDRICH, Hugo. Estrutura da Lírica Moderna. Tradução de Marise M. Curioni e Dora F. da Silva. São Paulo: Livraria Duas Cidades, 1978.

MALLARMÉ, Stéphane. Les mystère dans le lettres In: Revue Blanche, 1896. Disponível em: $<$ http://gallica.bnf.fr/ark:/12148/bpt6k6573791h/f21.image.r=proust $\% 20$ contre $\% 201 \% 2$ 7obscurit\%C3\%A9\%20revue\%20blanch\%C3\%A9.langPT> Acessado em 13 jan, 2017.

NORA, Pierre. Entre memória e história: a problemática dos lugares. Tradução de Yara Aun Khoury. In: Proj. História, São Paulo, $10 \quad$ (dez) 1993. Disponivel em: <http:// revistas.pucsp.br/index.phprevph/article/viewFile/12101/8763> Acessado em 15 mai. 2016. Disponível em:
PROUST, Marcel. Contre I'obiscurité. In: Revue Blanche, 1896. <http://gallica.bnf.fr/ark:/12148/bpt6k6573791h/f21.image.r=proust $\% 20$ contre $\% 201 \% 2$ 7obscurit\%C3\%A9\%20revue\%20blanch\%C3\%A9.langPT> Acessado em 13 jan, 2017. SISCAR, Marcos. Poesia e Crise: ensaios sobre a "Crise da Poesia" como topos da modernidade. Campinas: Unicamp, 2011.

WILSON, Edmund. O Castelo de Axel: ensaios sobre a literatura imaginativa de 1870 a 1930. Tradução de José Paulo Paes. São Paulo: Companhia das Letras, 2004.

\footnotetext{
${ }^{6}$ Muito pelo contrário, a proposta teórica de Berardinelli nos sugere uma ampliação do arsenal teórico, ou seja, uma teoria que se molda conforme o objeto. Essa flexibilidade reflexiva mostra a maturidade intelectual gerada pela própria dificuldade de apreensão da poesia moderna.
} 